\title{
Angeborene Panophthalmitis mit Bacillenbefund bei einer Ziege, nebst Bemerkungen über fötale Angenentzündangen und Bildungsanomalieen des Auges im Allgemeinen.
}

Von

\author{
Prof. Th. Leber \\ in Heidelberg \\ und
}

Dr. C. Addario,

Privatdocenten der Ophthalmologie in Catania.

Hierzu Taf. VIII, Fig. 1-3.

Die Literatur ist reich an Beobachtungen von angeborenen Anomalieen und Erkrankungen des Auges, welche darthun, dass die nach der Geburt an diesem Organ auftretenden Entzündungen, wenigstens zu einem grossen Theil, auch im intrauterinen Leben yorkommen. Nur selten besteht allerdings der entzündliche Process zur Zeit der Geburt noch fort, wenn wir von den nicht eigentlich hierhergehörigen Fällen absehen, wo die Entzündung erst während einer sehr in die Länge gezogenen Geburt durch Infection in den Geburtswegen zu Stande kommt; aber ihre Folgezustände gestatten oft noch einen sicheren Rückschluss darauf, dass wäbrend der Fötalzeit eine Entzündung vorbanden war. Ueber die Ursachen und die Entstehungsweise der letzteren sind wir allerdings noch sehr unvollkommen unterrichtet. Es ist bekannt, dass dabei die Syphilis eine sehr wichtige Rolle spielt, dass aber auch andere infectiöse Krankheiten in Betracht kommen können. 
Von Erkrankungen des Auges liegt z. B. ein Fall von Panas $^{1}$ ) vor, bei welchem eine angeborene Phthisis bulbi des einen Auges auf eine intrauterin entstandene Variola zurïckgeführt werden musste.

Ueber die Entstehung der fötalen Entzündungen überhaupt ist schon eine grosse Zahl von Beobachtungen und Untersuchungen gemacht worden, durch welche die Möglichkeit des Ueberganges krankheiterregender Mikroorganismen verschiedener Art von der Mutter auf die Frucht sicher gestellt wird. Die Gefässe der Placenta geben für diesen Uebergang ein schwer zu passirendes Hinderniss $a b$, welches aber für die verschiedenen Mikroorganismen nicht gleich gross ist. Bei denjenigen Krankheiten, wo ein solcher Uebergang wirklich stattfindet, erfolgt derselbe durchans nicht regelmässig, sondern stellt im Gegentheil ein mehr oder minder ausnahmsweises Vorkommmiss dar. Die Möglichkeit des Ueberganges ist für eine ganze Anzahl verschiedenartiger Mikroorganismen dargethan, von welchen wir hier nur die wichtigsten beim Menschen vorkommenden anführen wollen: die Bacillen des Milzbrands, des Rotz, der Tuberculose, des Typhus, den Pneumococcus, den Streptococcus und den Staphylococcus aureus, bei welchem letzteren der Cebergang besonders leicht zu erfolgen scheint.

Eine wichtige Bedingung für das Zustandekommen des Ueberganges ist nach den vorliegenden Untersuchungen eine vorausgehende Erkrankung der Uterusschleimhaut und der Placenta, welche durch die betreffenden Mikroorganismen selbst bewirkt wird und die in einer Blutung oder in einem entzündlichen Process bestehen kann. So erklärt es sich, dass verschiedene Beobachter in Bezug auf die Möglichkeit des Ueberganges zu einander direct widersprechen-

1) Panas, Cas d'atrophie congénitale de l'oeil gauche par suite de variole intra-utérine. Gaz. des Hôp. 1871. 5. déc. p. 571. 
den Ansichten kommen konnten, und dass die Uebertragung auch bei so stark ansteckenden Krankheiten, wie der Milzbrand, nur in ausnahmsweisen Fällen zu Stande kommt.

Bei einem Theil dieser intrauterinen Entzindungen ist nach der Natur und dem Sitz des Processes in Bezug auf den Foetus eine ektogene Entstehung anzunehmen, d. h. eine solche, bei welcher die Krankheitserreger dem an der Körperoberfäche liegenden Organ direct, also durch das Fruchtwasser zugeführt werden; in anderen Fällen muss es sich um eine endogene, d. h. durch den fötalen Kreislauf vermittelte Entstehung handeln; in einer weiteren Zahl von Beobachtungen bleibt die Entstehungsweise zweifelhaft.

Der elktogenen Entstehung sind vor Allem gewisse Fälle von angeborenen stationären Hornhautrüubungen zuzuschreiben ${ }^{1}$ ). Ueberall, wo aus der dichten, narbigen Trübung der Hornhaut, aus dem Vorhandensein einer vorderen Synechie, aus etwaigen, bei mikroskopischer Untersuchung nachweisbaren Defecten der Grenzmembranen, oder aus Staphylombildung auf einen abgelaufenen Geschwürsprocess geschlossen werden kann, wird dessen Entstehung, gerade wie nach der Geburt, auf Mikroorganismen zu beziehen sein, welche auf die Aussentäche des fötalen Auges gelangten und hier zur Entwicklung kamen. Die Gefässlosigkeit der fotalen Cornea ${ }^{2}$ ) macht es, ebenso wie am

1) Zusammenstellungen der Literatur der angeborenen Hornhauttrübungen finden sich $u$. A in folgenden Arbeiten:

Santo Domingo, Ueber angeborene Hornhauttrübungen. Inaug.Diss. r. Berlin 1894.

Alfr. Braun, Beiträge zur Lehre von den fötalen Augenentzündungen. Inaug.-Diss. v. Hoidelberg. 1895.

R. D. Cohn, Ueber einen Fali von Teratoma corneae congenitum mit vorderen und linteren Synechieen und Cataract. Inaug.Diss. v. Heidelberg. 1896.

2) Vgl. Th. Leber, Graefe-Saemisch's Handb. II. S. 334 . (1876). - Schöbl, Centralbl, f. prakt. Augenheilk. X. S. 321-326. (1886.) 
Angeborene Panophthalmitis mit Bacillenbefund bei einer Ziege etc. 195

entwickelten Organ, höchst unwahrscheinlich, dass die Mikroorganismen in solchen Fällen der Hornhaut auf dem Wege des fötalen Kreislaufs zugeführt werden.

Es liegt auf der Hand, dass derart entstandene Entziindungen auch tiefer greifen und ihren Ausgang in Phthisis bulbi oder totale Zerstörung des ganzen Augapfels nehmen können. Abgesehen von angeborenen Hornhautstaphylomen mit ihren verschiedenen merkwürdigen Complicationen sind daher auch gewisse Fälle von Mikrophthalmus und sogen. Anophthalmus bierher zu rechnen; auch der sog. Kryptophthalmus ist, als angeborenes totales Symblepharon, wohl nur durch eine ausgedehnte Entzündung an der Oberfläche des Sehorgans zu erklären.

Ferner ist es für die angeborenen Lipodermoide der Bindehaut und Hornhaut und die zuweilen damit verbundenen Colobome der Augenlider nicht unwahrscheinlich gemacht, dass hier ebenfalls entzïndliche Processe eine Rolle spielen, die zu abnormen Verwachsungen, zur Bildung amniotischer Stränge und Keimverlagerung den Anlass geben.

In manchen Fällen wurde zur Zeit der Geburt neben einem Leukom oder Staphylom der Hornhaut oder einer noch tiefer greifenden Zerstörung des ganzen Auges eine eitrige Conjunctivitis gefunden. Dies weist darauf hin, dass die Keratitis hier vermuthlich keine primäre, sondern durch die Bindehautaffection herrorgerufen war.

So beobachtete Rivaud Landrau (1857) ausgesprochene Bindehautblennorrhoe mit Phthisis bulbi an beiden Augen eines zwei Tage alten Kindes. Brann (loc. eit.) berichtet ibber einen von Th. Leber in der Heidelberger Augenklinilk beobachteten Fall von doppelseitiger eitriger Bindehautentzündung mit totalen Leukomen bei einem vier Tage alten Kinde. Fälle von Bindehautblennorrhoe bei Anophthalmus oder bei angeborener Phthisis bulbi wurden beobachtet von Wicherkiewicz, Th. Leber in

1) Rivaud Landran, Ophthalmie purulente chez le foetus. Ann. d'Ocul. T. XXXVII. p. 66-69. (1857.) 
der Göttinger Augenklinik, Kroll, Hilbert, Durlack. E. v. Hippel $\left.{ }^{1}\right)$ theilt einen Fall von doppelseitiger angeborener Plthisis bulbi aus der Heidelberger Augenklinik mit, der mit eitriger Conjunctivitis eomplicirt war und bei welehem es noch sieben Wochen nach der Geburt gelang, aus dem Bindehautsecret Pneumocokken zu zuichten, welche mit Wahrseheinlichkeit als die Erreger der Entziindung anzusehen waren. Der Mittheilung dieses Falles sind auch die Citate der Arbeiten der oben gemannten Autoren beigeftigt.

Einen Fall von perforirtem Homhautgesehwïr bei einer todt zur Welt gekommenen Frülgeburt berichtet Zehender"), ohne von einer gleichzeitigen. Bindehanterkrankung etwas $\mathrm{zu}$ bemerken, so dass es unentselieden bleibt, ob eine solche zu Grunde lag. Emmert) sal bei einem sieben Tage alten Mädehen ein dichtes "Leukom", das den grössten Theil der unteren Hälfte der Cornea einnalm und auf demselben, neben dem unteren Rande, ein sichelförmiges Geschwür, welches in etwa viel' Wochen ohne Perforation zur Heilung kam. Es bestand anfangs keime Conjunetivitis, ob das Geschwur sehon zur Zeit der Geburt vorhanden war, ist nicht direct beobachtet und es bleibt fraglich, ob man hier eine ektogene oder endogene Entstelmng der Keratitis annehmen soll.

Von den uns hier näher interessireuden Erkrankungen des Auges, welche auf endogene Infection zurückzuführen sind, sind zunächst die parenchymatöse Keratitis und der Hydrophthalmus anterior zu nennen. Soweit es sich um abgelaufene Processe handelt, dürfen wohl die meisten Fälle, bei welchen eine angeborene diffuse Hornhauttrübung nach der Geburt allmählich mehr oder minder sich aufhellt oder vollständig verschwindet, auf eine parenchymatöse Keratitis der Fötalzeit bezogen werden. Die Hornhauttrübung war in solchen Fällen zu-

1) E. v. Hippel, Ueber Anophthalmus congenitus. Dieses Areh. XLVII. 1. S. $227-241$. (1898.)

2) Zehender, Klin. Monatsbl. f. Augenheilk. 1863. S. 531 $-534$.

s) Emmert, Ulcevirtes Lenkoma comeae congenitum. Arch. f. Augenheilk. Y. S. $397-399$. (1876.) 
AngeborenePanophthalmitis mitBacillenbefund bei einerZiege etc. 197 weilen sehr intensiv, so dass die Prognose ganz unginstig gestellt wurde, bis die Trübung später, sei es spontan, sei es durch antisyphilitische Behandlung, sich aufzuhellen begann.

Die entzündliche Entstehung der Trübung kann zur Zeit der Geburt noch durch das Vorhandensein von leichter Injection oder wenigstens von Lichtscheu angedeutet sein. Von den uncomplicirten Fällen mit normaler Wölbung der Hornhaut hat man diejenigen zu unterscheiden, bei welchen die Comea und Sklerocornealgrenze abnorm vorgewölbt und ausgedehnt sind und welche den Uebergang zu der gewöhnlichen Form des Hydrophthalmus anterior mit durchsichtiger Cornea bilden. Man hat schon längst angenommen, dass der sogen. Keratoglobus auf einer zur Zeit der Geburt abgelaufenen Entziundung des vorderen Bulbusabschnittes beruhe, welche mit verminderter Widerstandsfähigkeit der Hornhaut und der sie ungebenden Theile der Bulbuskapsel einhergeht. Die Vermuthung, dass die zur Zeit der Geburt durchsichtige Cornea im früheren Stadium entzündlich getrübt gewesen sei, wird durch Fälle gestützt, wo die ektatische Cornea beim Neugeborenen oder etwas später noch mehr oder minder getrübt gefunden wird und sich erst später aufhellt.

E. v. Hippel ${ }^{1}$ ) hat ror Kurzem wichtige Beiträge zur Erkenntniss des Wesens dieser Erkrankungen geliefert, in denen er den Nachweis führt, dass in manchen Fällen die Trübung und Resistenzverminderung der Hornhaut durch einen flachen Substanzverlust an der Innenfläche der letzteren bedingt ist, und dass alsdann die Veränderung des

1) E. v. Hippel, Ueber Hydrophthalmus congenitus nebst Bemerkungen über die Verfärbung der Cornea durch Blutfarbstoff. v. Graefe's Arch. f. Ophthaim. XLIV. (1897). - Derselbe, Ueber die klinische Diagnose von Endothelveränderungen der Cornea und ihre Bedeutung für die Auffassung rerschiedener Hornhauterkranliungen. Sitzungsber. d. ophthalm. Gesellsch. f. 1898. S. 67. 
Hornhautparenchyms im Wesentlichen auf Quellung durch das Kammerwassex und nicht auf entzündlicher Infiltration beruht. Das Vorhandensein eines Ulcus internum corneae ergab sich bei der anatomischen Untersuchung eines doppelseitigen Hydrophthalmus anterior mit sebr dichter Tribung der Hornhäute, welche vier Wochen nach der Geburt stattfand. Für die Untersuchung am Lebenden erwies sich die Einträuflung von Fluoresceïn in den Bindehautsack als wichtiges diagnostisches Mittel, wodurch es sowohl längere Zeit nach der Geburt, als anch wiederholt bei Neugeborenen mit parenchymatösen Hornhauttrübungen gelang, Läsionen des Endothels mittels der dabei auftretenden Fluorescenz nachznweisen.

Wenn wir auch über die Entstehung dieser Veränderungen an der Innenfläche der Hornhaut noch gar keine directen Kenntnisse besitzen, so dürfte doch die Annahme nicht unberechtigt sein, dass es sich dabei um eine Wirkung durch den Blutkreislauf in die vordere Kammer importirter Mikrobien handelt.

v. Hippel betont aber mit Recht, dass nicht alle Fälle von sogen. parenchymatöser Keratitis gleicher Art sind und dass es darunter solche giebt, bei welchen eine Endothelveränderung nicht von wesentlicher. Bedeutung sein kann.

Es scheint dies besonders bei manchen Fällen von an Rande beginnenden skJerosirenden Trübungen der Fall zu sein, wie solche im Ausgangsstadium auch zuweilen als angeborene Anomalieen beobachtet worden sind.

Hierher gehörige Beobachtungen verschiedener Autoren sind in ziemlicher Anzahl in den oben citirten Dissertationen von S. Domingo und Braun gesanmelt, auf welche wir hiermit verweisen.

Es frnden sich in der Arbeit von Braun, unter Nr. 10 und Nr. 20 auch zwei Fälle ans der Heidelberger Augenklinik, bei denen ein syphilitiseher Ursprung zu vermothen, aber nicht sicher nachzuweisen war. Im ersten Fall, mit dichter Trübung aber ohne auffallende Ektasie đer Hornhaut trat während einer 
Inunctionscur bedentende Aufhellung ein. Im zweiten Falle, $m$ it starker Ektasie, erzielte, nachdem Hg-Einreibungen wenig Erfolg gehabt hatten, am einen Auge eine Iridektomie bedeutende Besserung, während das andere Auge obne Operation durch Auftreten eines eitrigen Geschwürs verloren ging, worauf wenige Tage nachher der Tod erfolgte.

Nicht so gar selten sind Ausgänge fötaler Iritis oder Iridochorioiditis, einfache bintere Synechieen, Pupillarverschluss, adhärente Cataract, Glaskörperdegeneration, Netzhautablösung, Phthisis bulbi oder Status glaucomatosus.

Schon 1869 hat v. Muralt $\left.{ }^{1}\right)$ über eine Reihe von Fällen von angeborener Bulbusektasie nach intrateriner Iridochorioiditis aus der Horner'schen Klinik berichtet. Der anatomische Befund des einen dieser Fälle ist später von $\mathrm{Haab}^{2}$ ) genauer besehrieben worden, wobei sich ergab, dass die Ektasie der Cornea nielit auf vordere Synechie durech Bulbusperforation, sondern auf Secundärglaukom durch Ausgänge von Iridochorioiditis mit Pupillarversehluss zu bexiehen war. Hierher gehört auch die Beobachtung Lawson's ${ }^{3}$ ) von abgelaufener Iritis mit Pupillarverschluss bei einem 7 monatlichen hereditär-syphilitischen Kinde, welches nach der Geburt niemals Zeichen von Entzündung dargeboten hatte.

Thier ${ }^{4}$ ) berichtet ferner über den anatomischen Befund bei einem 3wöchentlichen Kinde, welches mit abgelaufener Iridochorioiditis zur Welt kam und bei welchem ausser den Folgezuständen dieses Processes auch eine persistirende Arteria hyaloidea gefunden wurde.

Von besonderem Interesse für die vorliegende Arbeit würde eine Mittheilung von A. Richter ${ }^{5}$ ) über eine angeborene Er-

1) v. Muralt, Ueber Hydrophthalmus congenitus. Inaug.-Diss. Zürich. 1869.

2) Haab, Beitr. zu d. angeb. Fehlern d. Auges. Intrauterine Iridochorioiditis. Dieses Arch. XXIV. 2. S. 272.

$\left.{ }^{3}\right)$ Lawson, Case of intra-uterine syphilitic iritis. Med. Times and Gaz. Vol. 50. p. 363. 1875.

*) Thier, Demonstration eines Falles von Cyclitis foetalis. Sitzungsber. d. ophthalm. Gesellsch. f. 1896. S. 317.

$\left.{ }^{5}\right)$ A. Richter, Drei Fälle von angeborener Verfüssigung des Glaskörpers bei Füllen. Berl. thierärztl. Wochenschr. VI. S. 81. Ref. in $\vee$. Michel's Jahresber. $f, 1891$. 
krankung des Glaskörpers bei Füllen sein, wenn die Angaben über dabei gefundene Mikroorganismen als zuverlässig betrachtet werden dürften. Wir bedauern sehr, dass uns nicht das Original dieser Mitheilung, sondern nur ein Referat über dieselbe zugänglich ist.

Es handelt sich im Wesentlichen um flottirende Glaskörpertrübungen nnd um einen als persistirende Arteria hyaloidea angesprochenen Strang in der Achse des Glaskörpers, bei drei Füllen, von denen zwei denselben Eltern extstammten.

Die in einem Falle vorgenommene anatomische Untersuehung ergab, ausser den im Leben geselhenen Veräpderungen, theilweise Netzhautablösung und Degeneration zweier Augenmuskeln. ,Sowohl im Giaskörper als in den degenerirten Stellen der Augenmuskeln fanden sich unzählige Cokken verscliedenster Art."

Das Torkommen in den Augenmuskeln ohne Angabe entsprechender Erscheinungen von entzündlicher Reaction und die verseliedene Art der Mikroorganismen lässt doch sehr daran denken, ob es sich hier neht rm eine postmortale Entwicklung gehandelt haben könme.

Wir möchten unsere Besprechung auf die oben betrachteten Krankheitszustände beschränken und auf seltenere Vorkommnisse und ophthalmoskopisch diagnosticirbare Veränderungen, deren Entstehungszeit und Dentung oft sehr unsicher ist, nicht weiter eingehen. Fis ist hier auch nicht der Ort, die Entstehungsweise der angeborenen Bildungsfehler im engeren Sinne des Wortes im Einzelnen zu besprechen.

Die hier schwebenden Fragen scheinen uns überhaupt noch nicht ganz spruchreif zu sein und es liegt auf der Hand, dass zu deren Entscheidung die Verallgemeinerung einzelner, wenn auch noch so typisch erscheinender Fälle micht ausreicht, sondern dass ein möglichst umfassendes Beobachtungsmaterial dabei verwerthet werden muss. Doch möchten wir einige allgemeiner gehaltene Bemerkungen darüber hier beifügen, welche vielleicht etwas zur Verständigung über die streitigen Fragen beitragen können.

Für diejenigen Anomalieen, welche sich als ein Stehenbleiben auf einer frìheren Entwicklungsstufe auffassen lassen, 
Angeborene Panophthalmitis mitBacillenbefund bei einer Ziege etc. 201 kann es nicht als eine wirkliche Erklärung bezeichnet werden, wenn man sie auf eine Hemmung der normalen Entwicklung zurïckführt, obne zugleich die Ursache dieser Entwicklungshemmung anzugeben. Nun ist doch nicht wohl zu bezweifeln, dass eine fötale Erkrankung die Entwicklung, sei es des ganzen Auges, sei es eines seiner Theile, hintanzuhaiten im Stande ist; die Annahme einer Entwicklungshemmung schliesst also die einer fötalen Entzündung nicht nur nicht aus, sondern es dürfte sich, unserer Meinung nach, überhaupt für die erstere, wenn man von Verletzungen absieht, kaum eine andere Ursache als eine fötale Krankheit angeben lassen.

Abgesehen von Hindernissen, welche der Bethätigung des ursprünglichen Bildungstriebes sich entgegenstellen, können natürlich auch Anomalieen des Bildungstriebes selbst nach Intensität oder nach Qualität in Frage kommen, wenn es sich um ein Zuriickbleiben des ganzen Auges auf einer frïheren Bildungsstufe oder um ein zu geringes allgemeines Wachsthum desselben handelt. Es dürtte aber nicht wohl angehen, auf diese Ursache einen Mangel einzelner Theile des Auges oder das Ausbleiben des Verschlusses einer Spalte zurickzuführen, wenn alle übrigen Theile in normaler Weise ausgebildet sind, da sich doch die Folgen des mangelhaften Bildungstriebes auch an diesen in irgend einer Weise zeigen müssten. Je localisirter und je hochgradiger die einzeln dastehende Abweichung von der Norm ist, um so mehr wird man an eine Störung der Entwickelung durch eine äussere Einwirkung, ein Trauma oder eine sonstige krankheitserregende Ursache denken mïssen.

Für viele angeborene Anomalieen, welche man gemeiniglich für nicht krankhaften Ursprungs hält, wie die Colobome der Iris und Aderhaut, die Irideremie, das Persistiren von Resten der Pupillarmembran oder der Arteria hyaloidea, die Ektopie und das Colobom der Linse, die 
Mehrzahl de1 Fialle von Mikrophthalmus etc., ist als entscheidend gegen den Kranikhaften Ursprung angesehen worden, dass die klinische Beobachtung und selbst die anatomische Untersuchung dabei oft keine Residnen ron Entzündung erkennen lassen. Doch zeigt eine genauere Durchsicht der betreffenden Mittheilungen, dass diese Angabe durchaus nicht immer zutrifft und dass, zumal bei klinischer Untersuchung, eine sichere Entscheidung darüber zuweilen gar nicht möglich war. In anderen Fällen ist auch bei anatomischer Untersuchung die A uffassung des Befundes schwierig, und die Möglichkeit verschiedener Deutungen zuzugeben. Doch bleiben allerdings Fälle ubrig, in welchen eine sorgfältige anatomische Untersuchung keine sicheren oder überhaupt keine Zeichen früherer Entzündung nachwies. Kommen aber nicht auch nach der Geburt tiefgreifende Entzündungen des Auges vor, welche spurlos zurückgehen, und sollte dieselbe Möglichkeit nicht auch für das Foetusauge zuzugeben sein? Sollte es nicht möglich sein, dass solche Krankheitsprocesse tiefgreifende Störungen in der Entwicklung des Auges hervorbringen, deren Folgen uns als angeborene Anomalieen entgegentreten, wobei diese Anomalieen als solche uns keinen Aufschluss darüber zu geben brauchen, welcher Natur die Störung war, der sie ihre Entstehung rerdanken? Gewiss ist diese Möglichkeit nicht in Abrede zu stellen; wie aber der Vorgang im EinzeInen sich gestalten mag, kann nur durch Untersuchung specieller Fälle entschieden werden. Man wird sich aber nicht vorstellen dürfen, dass der krankhafte Process gerade nur an der Stelle localisirt gewesen sei, an welcher später der Bildungsfehler gefunden wird. Es beschränkt sich doch auch z. B. bei einem Colobom der Iris die Anomalie nicht auf das Vorhandensein eines umschriebenen Defectes der letzteren, sondern der Defect ist mit einer mangelhaften Entwicklung des ganzen betreffenden Abschnittes der Iris und der angrenzenden Theile des Auges combinirt, welche 
eine weit über die Grenzen des Defectes ausgebreitete Wirkung der Schädlichkeit voraussetzt. Wenn die Fötalspalte sich nicht schliesst, and kein Exsudat gefunden wird, welches den Schluss verhindert, so* kann dies daran liegen, dass der Krankheitsprocess das Wachsthum der ganzen Anlage des Auges beeinträchtigt hat, so dass die Ränder nicht bis zur Berührung einander entgegen wuchsen. Obwohl hier die Störung als eine ganz allgemeine gedacht werden kann, so werden sich doch ihre Folgen später nur an einer umschriebenen Stelle zeigen.

Bei Beachtung dieses Gesichtspunktes dürfte wohl eine Schwierigkeit wegfallen, welche die bisherigen Versuche gefunden haben, die Entstehung der Bildungsanomalieen auf krankhafte Processe zurückzuführen. Der Einwand ist in der That vollkommen berechtigt, dass man nicht einsehen kann, warum eine fötale Entzündung sich besonders häufig an der Stelle des Fötalspaltes localisiren soll, da man diese doch nicht als besonders disponirt dafür betrachten kann. Dieser Einwand wird aber hinfällig, wenn man in der angegebenen Weise beriicksichtigt, dass auch weiter verbreitete Entzündungsprocesse durch den Entwicklungszustand des Auges bedingte locale Bildungsanomalieen zur Folge haben können.

Die folgende Beobachtung ${ }^{1}$ ) einer doppelseitigen inneren Augenentzündung bei einer neugeborenen Ziege scheint uns deshalb von besonderem Interesse zu sein, weil es hier wohl zum ersten Mal gelungen ist, bei einer in der Fötalzeit entstandenen endogenen Augenentzündung in dem Vorkommen zahlreicher Bacillen mit grosser Wahrscheinlichkeit die Krank-

1) Eine kurze Mittheilung über diese Beobachtung wurde schon bei der letzten Versammlung der ophthalm. Gesellschaft in Heidelberg gemacht und ein Präparat davon vorgezeigt. (Vgl. Sitzungsbericht der XXVII. Versammlung, 1898, S. 315.) 
beitsursache nachzuweisen. Eine etwas ausführlichere Beschreibung dürfte daher gerechtfertigt sein.

Krankengeschichte.

Die Eigenthümerin brachte die junge Ziege, als diese acht Tage alt war, am 14. März 1897 nach der Angenklinik, da sie zwei bis drei Tage nach der Geburt des Thieres bemerkt hatte, dass es blind war. Das Mutterthier war stets in gutem Gesundheitszustande gewesen; hatte gut gefiessen und reichlich Milch gegeben. Es war viermal von demselben Bocke gedeekt worden, welcher ebenfalls gesund ist und andere Ziegen mit gesunder Nachkommenschaft gedeckt hat. Nach der ersten Paarung wurde eine Missgeburt, nach der zweiten eine ebenfalls missbildete und zugleich blinde Ziege geboren, nach der dritten der Gegenstand der vorliegenden Untersuchnng, nach der vierten Paarung drei gesunde Junge.

Status praesens: R. A. Mässige Injection. Comea klar. Pupille verengt; an ihren oberen Rande ist ein Exsudatfaden befestigt, welcher senkrecht über sie nach nnten hinwegzieht und an welchern ein kleines scheibenförmiges Exsudat anhängt, das der Iris aufliegt und frei in der vorderen Kammer beweglieh ist. Iris etwas verdickt und im oberen Theil in radiärer Richtung leicht gefaltet.

L. A. Starke Injection, Sklera von blänlicher Färbung. Zarte parenchymatöse Trübung der Hornhaut, dio nur am äusseren Rande Gefässe zeigt; an ihrer Hinterfläche und anf der Iris fibrinöses Exsudat, welches sich von nnten her bis zur Pupille erstreckt. Der obere Theil der Iris etwas faltig gewulstet, zahlreiche hintere Synechieen; anscheinend auch Exsudation in Glaskörper.

Das Thier wurde sogleich getödtet und die Augen frisch in $10 \%$ Formollösung gelegt. Die Section (Prof. E. . Hippel) ergab keine makroskopisehen Veränderungen der Körperorgane.

\section{Anatomische Untersuchung:}

der in Celloidin eingebetteten und im verticalen Meridian geschnittenen Augen.

Rechtes Auge. - Cornea, abgesehen von einigen neugebildeten Gefässen in der Randzone, nahe der Oberfäcle, und von zelliger Infiltration in deren Umgebung, normal.

In der vorderen Kammer findet sich ein hauptsächlich den unteren Theil derselben einnehmendes, lose liegendes Fibrin- 
gerinnsel, dessen Randtleile reichlicher mit Leukocyten infiltrirt sind. Dasselbe war auch im Leben beobachtet worden; sein Zusammenhang mit dem oberen Pupillarrande ist aber zufällig an keinem der Schnitte erhalten. Die Fontana'schen Ränme sind reichlich mit Leukocyten durchsetzt, besonders wo sie an die vordere Kammer anstossen. Die Leukocyten enthaiten zahlreiche, dem Pigmentepithel entstammende schwarze Pigmentkörnchen.

Die Iris ist stark hyperämisch und neben ihrem Ciliarrande, besonders um die Gefusse herm, stellenweise von Lenkocyten infilturt, beträchtlich verdickt und in eigenthümlicher Weise gefaltet. Die Verdickung betrifft besonders eine nicht weit rom Ciliarrande entfernte Zone, welche sich in Folge ihrer Dickenzunahme ganz an die hintere Flache der Hornhaut anlegt, so dass der peripher davon befindliche Theil der vorderen Kammer, bald auf einer, bald auf beiden Seiten, von dem tibrigen Theil abgetrennt wird. Die an den unteren Pupillarrand grenzende Zone ist nach hinten umgeschlagen und dadurch die Iris an dieser Stelle rerdoppelt. Der Zwisehenram ist dureh mässig zellemreiches Fibrin ausgefullt. Auch sonst ist die hintere Fläche der Iris unregelmässig und das Pigmentepithel zieht in Folge der Faltung mehrfach ziemlich tief in deren Gewebe hinein. Sie ist von einer mässig dicken, hauptsächlich aus Leukocyten bestehenden Exsudatschicht bedeckt. Am oberen Pupillarrand ist das Pigmentepithel in unregelmässiger Weise gewuchert und durchzieht als Netzwerk den angrenzenden Theil des Stroma's.

Die Linse ist normal.

Der Ciliarkörper ist vom Fontana'scken Raum aus eine Strecke weit dicht von Leukocyten infiltrirt. An seiner Innenfiäche erscheint die Zonula ziemlich locker mit den gleichen Zellen durchsetzt; nach einwärts werden diese allwählich zahlreicher and gehen in eine dichte Leukocyteninfiltration über, die den vordersten Abschnitt des Glaskörpers und die hintere Fläehe der Linse einnimmt.

Auch von den die hintere Kammer, die Zonulagegend und den vorderen Theil des Glaskörpers einnehmenden Leukocyten enthalten viele aus dem Pigmentepithel herstammende Pigmentkörnohen eingeschlossen; die Zahl dieser pigmenthaltigen Zellen ist um so grỏsser, je näher man dem Pigmentepithel kommt. Eine weitere Eigenthümlichkeit der noch auf der Wanderung begriffenen, lose in die Gewebe oder das Exsudat eingelagerten Leukocyten, die allgemein verbreitet und auch am linken Auge zu beobachten ist, besteht in dem Vorkommen zahlreicher, auf- 
fallend langer und verzweigter amöboider Fortsätze, die beim Menschen oder Kaninchen in diesem Grade der Entwicklung nicht yorzukommen pllegen.

Von der Hinterfläche der Linse aus zieht in der einen Hälfte des Auges eine Fortsetzung der hier vorhandenen eitrigen Infiltration, als dünne Schicht, in geringem Abstand von der Netzhant bis in die Gegend des Sehmerveneintrittes nach hinten.

Der grösste Theil des Glaskörpers zeigt nur eine ziemlich lockere Infiltration mit vereinzelten Lenkocyten. Erst an der Innenfläche der Netzhaut, besonders am hintersten Abschnitt derselben, erreicht die zellige Infiltration wieder einen beträchtlichen Grad, indem die unmittelbar an die Netzhaut grenzende Schicht des Glaskörpers ziemlich dicht von Leukoeyten and dazwischen von Fibrinnetzen eingenommen ist, deren Menge jedoch in geringer Entfernung von der Retina schon wieder erheblich abnimmt.

Die Netzhaut selbst ist in ihrer ganzen Ausdehnung trichterförmig von der Aderhaut abgelöst und der subretinale Strom ron eiweisshaltigem Transsudat ausgefüllt. Die Gefässe der Netzhaut sind stark ausgedehnt, besonders in der Faserschicht. Sie erheben sich zuweilen im Bogen etwas aber die Innenfläche der Membran oder ziehen eine Strecke weit auf derselben entlang. Alle Gefässe der Faserschicht zeigen stark mit Leukocyten infiltrirte Wandungen, an welche sich eine an Dichte almählich abnehmende Infiltration des umgebenden Gewebes anschliesst. Auch die ganze Faserschicht ist reichlich ron gleichen Zellen durchsetzt. Die übrigen Schichten sind wenig verändert, selbst die Stäbchenschicht ziemlich gut erhalten und die Henle'sche Querstreifnng der Stäbehenkörner sehr schön zu beobachten.

Die Chorioidea ist von normaler Dicke und zeigt keine entzündlichen Veränderungen. Nur auf einer Seite liegt in der Gegend des Orbieulus eiliaris im Suprachorioidalraum ein dünner, Hächenhafter Bluterguss, der an vielen anf einander folgenden Schnitten zu beobachten ist.

Der Sehnerveneintritt bietet im Wesentlichen dasselbe Verhalten wie die Faserschicht der Netzhaut.

Linkes Auge. - Cornea zeigt nur ganz leichte entzündliche Veränderungen.

Vorder"e Kammer seicht. Die Iris in grosser Ausdehnung der Hornhaut angelagert; der Rest des Kammerraumes theils mit geronnener Eiweissmasse, theils mit eitrig-fibrinösem Exsudat gefüllt. Letzteres bedeckt rorzugsweise die Vorderfläche der 
Iris, wo es den grössten Zellenreichthum besitzt; aber auch der Descemet'schen Nembran, deren Endothel gut erhalten ist, sind Leukocyten in mehrfacher Schicht aufgelagert, und die Fontanaschen Räume dicht mit denselben erfüllt.

Die Iris ist verdickt, ihre Gefässe stark ansgedehnt, ihr Gewebe zellig infiltrirt. Der Pupillarand ist der Linsenkapsel adhärent und auf einer Seite etwas nach hinten umgeknickt. Die Hinterfläche ist von einem Iocker mit Leukocyten durchsetzten Fibrinnetz bedeckt.

Die Linse ist unverändert. Das Exsudat an der Hinterfläche der Iris erstreckt sich nach den Seiten hin bis auf die Ciliarfortsätze und geht in die gleichfalls lockere, zellige Infiltration der Zonulagegend ïber.

Der Ciliarkörper ist, yon den Fontana'sehen Rärmen ansgehend, ziemlich stank zellig infiltrit.

Eine dichtere Eiterinfiltration tritt erst im Bereich des Glaskörpers auf, die im Allgemeinen von vorn nach hinten zunimmt. Im vorderen Abschnitt bleibt die zellige Infiltration mehr auf die seitlichen Theile beschränkt und erreicht nicht ganz den hinteren Linsenpol; im hinteren Abschnitt bildet sie eine, die Innenfläche der Retina überziehende Zone, die an Dicke bis $5 \mathrm{~mm}$ beträgt, in welcher aber die Dichtigkeit ganz eigenthümliche Verschiedenheiten darbietet.

An die Innenfläche des Ciliarkörpers grenzt zunächst eine Schicht zellenärmexen, fibrinösen Exsudates, auf welche erst die dichte Fiterinfiltration des Glaskörpers folgt. Die Zellen sind hier stark an einander gedrängt und in zierliche, durch die Structur des Glaskörpers bedingte, Reihen geordnet.

Zwischen dieser dichten Infiltration und dem zellenärmeren Fibrinnetz liegen an der ganzen Innenfüche des Ciliarkörpers, aber nur in dünner Schicht, zahlreiche, meist sehr grosse Pla agocyten, welche Bacillen und Eiterkörperchen eingeschlossen halten (vgl. Taf. VIII, Fig. 3), alle ungefähr gleich weit rom Ciliarkörper entfernt. Die Bacillen sind meistens sehr zalilreich und durch die ganze Zelle verbreitet, doch kommen auch Zellen mit nur wenigen Bacillen vor. An manchen erkennt man mit der grössten Deutlichkeit, dass sie ausser dea Bacillen auch mehrkernige Leukocyten, gewöhnlich zu zwei oder mehreren, aufgenommen haben. Die eingeschlossenen Leukocyten sind rundlich und enthalten mehrere kleine, bald nur schwach, bald noch gut gefärbte Kerne, sind aber immer frei von Bacillen, welche sich überall an ibre Zwischenräume halten. Die der Phagocytenzelle 
zugehörigen Kerne sind gut gefärbt, grösser und auffallend unregelmässig gestaltet; sie sind oft durch die Leukocyten platt gedrüekt und an den Rand der Zelle gedrängt. Das Verhalten der Bacillen werden wir unten im Zusammenhang besprechen. Gleiche Phagocyten kommen, wie schon hier bemerkt sei, anch im hinteren Abschitt des Auges, besonders in dem die Netzhaut überziehenden eitrig-fibrinösen Exsudate und in der Netzhaut selbst ror.

Wie am rechten Auge, so haben anch hier sowohl die Eiterkörperchen der vorderen Kammer, als auch die hinter der Iris und in der Nähe des Ciliarkörpers vielfach rom Pigmentepithel stammende Pigmentiöornchen aufgenommen. Die Menge der pigmenthaltigen Zellen nimmt aber nach einwärts rasch ab, und sie vedieven sich bald völig: im hinteren Theil des Glaskörpers und an der Innenfüblie der Retina werden sie ganz rermisst. Die Phagocyten der Ciliargegend sind tast immer von Pigmentkörnchen frei. Nur einige selliessen vereinzelte Pigmentkörnchen ein, die vielleielt den darin entlaltenen Leukocyten angehören.

An der Ora serrata fungt die Hyaloidea an sieh ron der Netzhaut zuridkzuziehen, so dass zwischen dieser und dem Glaskörper ein breiter, mit eitrig-fibrinösem Exsudat erfullter Zwisehenraum entstelit. Das Verhalten des Gewebes auf leiden Seiten der Hyaloidea ist dabei drrehaus verselienten. Thre äussere Fläehe ist ron einer dünnen Lage diehtgedrängter Eiterkörperchen überzogen, die sich nach rivekwärts almählich lockern; bei sehwacher Vergrösserung erscheint sie dadurch an gefärbten Präparaten als ein dunkler Streifen, welcher in einigem Alstand der hinteren Augenwand etwa parallel verläut. Der vor der Hyaloidea liegende Glaskörper ist dagegen zuräelist fargt zellenfrei und massenhaft von freien Bacillen durchsetzt. Erst weiter nach vorn nimmt die Eiterinfiltration beträehtlich $z u$, bleibt aber aul einen ziemlich geringen Raum beschränkt, so dass der grössere Theil des Glaskörpers, von der Hinterfäche der Linse ab nach rïickwärts, von eilriger Infiltration ziemlich frei ist, am weitesten in der Richtung nach dem Sehnerveneintritt hin.

Die abgelöste Hyaloidea lässt sich in der" oben gesehilderten Weise nur eine Strecke weit nach einwärts sicher verfolgen. Die eitrige Infiltration fängt daan an, auch ihre Innenfläelie zu bedecken, und sie ist zuletat zwischen den Eiterkörperchen nicht mehr erkennbar. Eine Fortsetzung der ihr entsprechenden Zone dichter Eiterinfiltration zieht sich aber, als bogige Kinie, ununter- 
brochen bis zur anderen Seite hinüber. Nach der Retina zu nimmt die Dichtigkeit der Eiterinfiltration schon in kurzem $\mathrm{Ab}$ stand von dieser Zone wieder beträchtlich zu.

Ausser der soeben beschriebenen Zone dichter Fiterinfiltration erkennt man in dem die Innentläche der Retina bedeckenden eitrig-fibrinösen Exsudat noch eine weitere Zone gleicher Art, aber von abweichendem und sehr eigenthümlichem Verlauf. (Vgl. Taf. VIII, Fig. 1.) Dieselbe stellt sich für das blosse Auge als eine wellig verlaufende Linie dar, deren Hervorragungen und Vertiefungen den kleinen Falten, welche die Innentläche der Netzhaut hier darbietet, in regelmässiger Weise entsprechen. Zwischen der Innenfläche der Netzhant und der erwähnten Zone findet sich überall ein $Z$ wischenraum, der von zellenarmem, fibrinösem Exsudat eingenommen ist. Hieraus folgt dann, ganz seharf abgesetzt, die sehmale Zone dichter Infiltration, welche sich glaskörperwärts allmällich Iockert.

Sehr merkwürdig ist nun das gegenseitige Verhalten der beiden Infiltrationszonen, von welchen die eine der Kürze halber als flache Zone (Fio. $1, f$ ), die andere als wellige Zone (Fig. 1, w) bezeichnet werden soll. Die flache Zone zieht nämlich durch die wellige Zone quer hindurch, so dass sie bald durch die Einsenkungen, bald durch die Vorragungen der letzteren zu verfolgen ist. An denjenigen Stellen, wo sie retinalwärts ron der welligen Zone durch das zellenarme Gebiet hindnrehzieht, ist sie immer schwächer ausgesprochen, als da wo sie glaskörperwärts von der welligen Zone verläuft, gleichsam als ob die Eiterkörperchen durch einen von der Höhe dex Netzhautfalten ausgehenden Einfluss aus den betreffenden Strecken der flachen Zone nach einwärts verdrängt worden wären. Wo dagegen die flache Zone glaskörperwärts ron der welligen Zone verläuft, ist sie stärker entwickelt und auch der Zwischenraum von einer dichteren, fast gleichmässigen Infiltration eingenommen.

An der nach der Retina gekehrten Grenze der flachen Zone finden sich auch regelmässig bacillenhaltige Phagocyten von der oben beschriebenen Art in das Exsudat eingelagert, während dasselbe sonst nirgends Bacillen enthält. In den glaskörperwärts von der welligen Zone und retinalwärts von der flachen Zone begrenzten Bezirken zeigt ein grösserer Theil der Eiterkörperchen keine Kernfärbung, ein anderer Theil deutlichen Chromatinschwund.

An einigen Schnitten tritt in der Achse des Glaskörpers eine in zwei Aeste getheilte bluthaltige Arterie hervor, deren

v. Graefe's Archiv für Ophthalmologie. XIVIII. 1. 
weiterer Verlauf sich nicht verfolgen lässt, da die betreffenden Schnitte leider verloren gegangen sind; ihre Richtung nach der Papille hin zeigt aber, dass es sich wohl um die Arteria hyaloidea handelt, welche bei Thieren nach der: Geburt oft noch eine Weile persistirt. Die Wand dieser Arterie ist dicht zellig infiltrirt; dann folgt eine Zone zellenarmen fibrinösen Exsudates und darauf eine Zone dichter eitriger Infiltration, so dass hier ganz dasselbe Verhalten wiederkehrt, wie an der Innenftäche der Retina. Es fellt hier anch nicht die Einlagerung bacillenhaltiger Phagocyten an der Grenze der dichteren Infiltration. Diese Uebereinstimmung dentet darauf hin, dass wohl die Blutgefässe fur die Entstehnag der beschriebenen Zonen von Bedeutung sein mögen. Wan sieht auch regelmässig anf der Höhe der Netzhantfalten ein grösseres Gefäss nach einwärts vorspringen. Eine weitere Uebereinstimmung zeigt sich an kleineren Gefässen der Netzhaut, besonders im vorderen Abschnitt derselben. Aneh diese zeigen, auf dem Quersehnitt, in der Umgebung der zellig infiltrirten Wandung einen Ring von zellenarmer fibrinöser Exsudation, auf welchen dann erst die diese Gegend einnehmende dichte Eiterinfiltration folgt. Bacillen wurden weder im Lamen, noch in der Umgebung dieser Gefässe gefunden; es liegt somit kein Anhaltspunkt vor, dieses Verhalten ani von Mikrobien ausgenbte chemotactische Einflüsse zu beziehen.

Die nur wenig abgehobene Netzhaut ist besonders in ihren inneren Schichten eitrig infiltrirt, am meisten im linteren Abselnitt und, auf der einen Seite, nach vorn rom Aeruator. Wie schon bemerkt, zeigt sie in der Umgebung der Papille eine Reibe kleiner, steil nach innen rorspringender Falten. Dieselben finden sich aber in ansgesprochenerem Maasse nur an seitlich von der Papille gefallenen Schnitten, wälirend an den durch die Mitte gehenden die Oberfläehe ziemlich eben ist. Die oben beschriebenen Zonen dichterer Eiterinfiltration des Glaskörpers finden sich hier ebenfalls, laufen aber in geringem Abstand ungefähr parallel neben einander bis in die Nähe des Aequators, wo die Hyaloidea mit ibrer Infiltrationszone stärker abgehoben wird und so zur Ora serrata hinzielt.

Die Nervenfaserschioht ist in Folge der eitrigen Infitration von dem angrenzenden eitrigen Exsudat oft gar nicht deutlich zu unterseheiden; sie ist auch sonst weit kernreicher als normal. Die Wandungen der grösseren Gefässe sind, wie am rechten Auge, stark von Leukocyten durchsetzt. Das Verhalten der sie umgebenden Exsudation wurde schon oben geschildert. 
Sehr anfallend treten im hinteren Abschnitt die Oapillaren als zusammenhängendes Netzwerk mit erheblich vermehrter Zahl der Kerne hervor. Weiter nach vorn finden sich zahlreiche, stark mit Blut erfüllte Capillaren, deren Wandungen in dem zellig infiltrirten Gewebe wenig sichtbar sind. Die Ganglienzellen sind zum Theil deutlich verändert, aber grösstentheils als solche nicht genügend zu erkennen. Die übrigen Schichten sind im hinteren Abschnitt nicht erheblich verändert, nur die Stäbchen etwas deformirt und die Aussenfläche der Retina von vereinzelten oder eine dïnne Schicht bildenden Lenkocyten bedeckt.

In der Aequatorialgegend und nach vorn von derselben erstreckt sich die eitrige Infiltration stellenweise von der Faserschicht aus mehr oder minder weit auf die übrigen Netzhautschichten und bringt deren Elemente zum Schwund. In gewisser Ausdehnung ist sogar die ganze Dicke der Netzhaut in diese Degeneration hineingezogen. Von der Stäbchenschicht ist hier nichts zu sehen; das Pigmentepithel schickt zapfenartige Auswüchse in die nach innen angrenzende Schicht hinein. Die innere Körnerschicht ist zum Theil rölig atrophirt; an iluer Stelle finden sich, ausser mehrkemigen Leukocyten, grosse ovale Kerne; die äusseren Körner sind gelockert und bilden unregelmässige Hervorragungen an der äusseren Grenze dieser Schicht. In der so veränderten Retina liegen zahlreiche, grosse, bacillenhaltige Phagocyten, bis an die Grenze der äusseren Körnerschicht; desgleichen in dem eitrigen Exsudat an der Innenfläche der Retina. Weiter nach rückwärts werden die Phagocyten spärlicher; man bemerkt noch kleinere bacillenhaltige Zellen in der Gegend der veränderten Faserschicht, worauf sie sich allmählich verlieren. Doeh sind bacillenhaltige Phagocyten anch im hinteren Abschnitt der Netzhaut vielfach $\mathrm{zu}$ finden, zum Theil unmittelbar neben dem Sehnerveneintritt; sie liegen dann, wie schon bemerkt, regelmässig dicht nach aussen von der flach verlaufenden, vermuthlich der Hyaloidea entsprechenden Infiltrationszone. Die Sehnervenpapille zeigt die gleichen Verändernngen. wie die Nervenfasersehicht.

Die Chorioidea ist in ihrer grössten Ausdehnung ziemlich noxmal; an der Innenfläche des Pigmentepithels und des Tapetum lucidum findet sich eine geringe Auflagerung ron Lenkocyten. Nur an einer unweit des Ciliarkörpers gelegenen Stelle, wo auch die Netzhaut stärker verändert ist, zeigt sie sich durch Leukocyteninfiltration erheblich verdickt und an ihrer Innenfläche von einer Schicht eitrig-fibrinösen Exsudates überzogen. 


\section{Bakteriologische Untersuchang.}

Da ror dem Einlegen der Augen in Formollösung leider keine Culturversuche gemacht worden waren, so kamn hier nur über das Ergebniss der Färbungsversuche berichtet werden, wobei wieder beide Angen gesondert zu besprechen sind.

Linkes Auge. - An diesem Auge waren dureh Furbung: mit wässeriger Gentianariolettlösung in der Wärme im Glaskörperraum nod der Retina zahlreiche Bacillen nachzuweisen, die als schlanke, an den Enden gerundete Stäbchen ron $1-3 \mu$, gewöhnlich $1,5-2 \mu$ Länge und etwa $1 / 3 \mu$ Dicke ersehienen.

Ohne Zubilfenahme von Erwärmen gelang deren Färbung mit der gleichen Lösung nieht, wie auch sonstige Färbungsmethoden anfangs versagt hatten. Die Bacillen nehmen besonders den an die abgelöste Hyaloidea grenzenden, von Eiterkörperchen stellenweise freien Theil des Glaskörpers ein, finden sich aber auch in Menge in dem eitrigen Exsudat zwischen dem abgelösten Glaskörper und der Retina, sowie in stärker eitrig reränderten Theilen der letzteren. Sie liegen theils frei, mehr oder minder zahlreich odel dicht zwischen den Zellen verbreitet, theils anch in Eiterkörperchen eingesehlossen. Mit der gleichen Wethode treten atch in den oben erwänten Phagocyten nahe der Innenflache des Ciliarkörpers und der Netzhaut mehr oder minder zahlreiche Bacillen hervor, deren Aussehen bei dieser Färbungsmethode nicht wesentich ron dem der übrigen abweicht (Taf. VIII, Fig. 3).

Dasselbe Ergebniss lieferte Furbung mit Carbolgentiana und Differentirung mit Alkohol. Zwisehen den bacillenhaltigen Eiterkörperchen traten hier in der eitrig veränderten Retina und im Glaskörper massenhafte Bacillencolonieen hervor. Anch mit Delafield's Haematoxylinlösung nahmen die Bacillen Fürbung an, wenn damit äberfärbt und mit HCl-Alkohol differenzirt wurde. Es fanden sich an solchen Präparaten enorme Mengen freier Bacillen, besonders in der Gegend der abgelösten Hyaloidea, aber viele davon schwach oder kaum gefärbt und num eben ertsennbar, dicht beisammen liegend, wie in Reineultur; dazwischen lagen einzelne, schön und intensiv gefürbte. Die Bacillen in den grossen Zellen der Ciliargegend hatten wur eine schwache Fürbung angenommen.

Bei Farbung mit der Ehrlich'schen und Ziehl'schen Methode ftar den Nachweis von Tuberkelbaillen wurden unsere 
Mikroorganismen entfärbt, sowohl durch 20\% Salpetersäure, als durch $5 \%$ Schwefelsäure; sie waren aber bei nur 30 Secunden dauernder Einwiwkng der Säure noch immer erkennbar. Bei Nachbehandlung mit sauerem Methylenblau wurden sie blau gefärbt. Weniger gut färbten sie sich durch Löffler's Methylenblan, selbst beim Erwärmen.

Wesentlich anders war das Verhalten bei Anwendung der Gram'schen und der Weigert'schen Färbungsmethode.

Mit der Gram schen Methode färbten sich die freien und in Eiterkörperchen eingeschlossenen Bacillen im Glaskörper wnd der Retina uberhaupt nicht oder nu ganz sehwach und andeutungswejse, dagegen nahmen die in den grossen Phagocyten eingeschlossenen Bacillen schöne und charakteristische Färbung an. Besonders zahlreich waren die Bacillen in den Phagocyten an der Innenfäche des Ciliarkörpers; weniger zahroich fanden sie sich in der Retina, wo die Phagocyten theils in einem Iockeren, eine Strecke weit fortlaufendem Zuge, theils in klemeren Gruppen auftraten. Dazwischen lagen hie und da vereinzelte Bacillen, von denen sich nicht sicher feststellen liess, $o b$ sie ebenfalls in Zellen eingeschlossen waren.

Diese intracellulären Bacillen sind von derselben Grösse wie die freiliegenden, erscheinen aber etwas dicker und plumper als bei den übrigen Färbungsmethoden. Selrr auffallend ist an denselben das Vorkommen dunkel gefärbter Körnchen im Inneren, von derselben Art, welche Ernst bei Methylenblaufärbung an den Xerosisbaeillen entdeckt und zuerst für Sporen gehalten hat. (Taf. VIII, Fig. 2.) An der Gleichartigkeit mit den Ernst'sehen Körnern ist, wie gleich hier bemerkt sein mag, um so weniger zu zweifeln, weil diese auch bei den Xerosisbacillen, wie der Eine von uns gefunden hat, durch die Gram'sche Methode ebenfalls darstellbar sind.

Die in den Phagocyten eingeschlossenen Bacillen zeigen eine blassviolette oder röthliche Färbung, gegen welche die dunkel gefärbten Körner sich scharf abheben. Letztere liegen meist an. beiden Enden des Bacillus, dessen Länge dabei beträchtlich. schwankt. Bei den kleinsten Formen liegen die Körner ganz dicht beisammen, nur durch einen ganz feinen Zwischenraum getrennt; mit zunehmender Länge des Stäbchens treten die Körner weiter, auseinander, so dass ihr Abstand das Doppelte bis Vierfache ihrer Dicke und darüber beträgt. Andere Bacillen, von grösserer Länge, enthalten drei bis vier solcher Körnchen, von denen immer je zwei am Ende des Bacillus gelegen sind. 
Nicht alle in einer Zelle enthaltenen Bacillen besitzen diese Körnchen, auch kommen Zellen vor, in denen sämmtliche Bacillen körnchenfiei sind.

Das Aussehen und die Lage dieser Körnchen stimmt vollkommen mit dem der Xerosis- und der Diphtherie- und Pseudodiphtheriebacillen iberein. Anch bei letzteren haben wir gefunden, dass mit der Gram'schen Methode der Bacillus, abgesehen von den Körnern, noch eine schwache Färbung behält, während mit Löffler's Metlyylenblan nur die Körner deutliche Färbung behalten, so dass zur Färbung des ganzen Bacillus noch eine Nachfärbung nothwendig wird.

Das Verhalten gegenüber der Weigert'schen Methode stimute insofern mit dem bei der Gram'schen überein, als auch hier, zwar nicht ausseliliesslich, aber doch vorzugsweise, die in den Phagocyten eingeschlossenen Bacillen gefärbt wurden. Die freien Bacillen des Glaskörpers blieben grösstentheils angefurbt, es fanden sich aber dazwischen zahlreiche vereinzelte Exemplare, welche Färbung angenommen hatten. Der Vergleich mit den entsprechenden Stellen der mit wässerigem Methylviolett oder mit Haematoxylin gefärbten Präparate ergab, dass diese gefärbten Bacillen nur einen sehr kleinen Theil der daselbst vorhandenen darstellten. Diese Ungleichheit der Färbung lässt sich wohl am besten durch die Annahme erklären, dass die Mehrzalil der Baeillen abgestorben und secundär verändert war, wäbrend einzelne ilrre Lebensfäliggkeit behalten hatten.

In den übrigen Theilen des Anges wurden keine Mikroorganismen gefunden, ebenso wenig irgendwo im Inneren von Blutgefässen.

Rechtes Auge. - Nach den soeben geschilderten $\mathrm{Er}^{-}$ gebnissen war es ïberraschend, dass an dem rechten, allerdings viel weniger stark erkrankten Auge zunächst gar keine Mikroorganismen nachzuweisen waren, auch nicht mit den Methoden, welche am linken Auge ein positives Resultat gellefert hatten, weder mit erwärmter wässeriger Gentianaviolettlösung, noch mit der Gram'schen und Weigert'schen Methode. Dagegen gelang später der Nachweis dureh Ueberfärben mit Delafield's Haematoxylin und Differenziren mit HCl-Alkohol. In einem Theil des vorderen Glaskörperabsehnittes, nicht weit ron der Innenfläche des Ciliarkörpers, der keine dichte Eiterinfiltration, sondern nur eine lockere Einlagerung von Lenkocyten wit amöboiden Formen darbot, fanden sich jetzt zahlreiche, schlanke, oft leicht gebogene freie Bacillen, deren Länge der des anderen 
Auges theilweise gleich war, sie aber nicht selten bedeutend ubertraf. Thre Dicke betrug, wie links, etwa $1 / 3 \mu$, nur wenige hatten aber eine Länge von nur $1-2 \mu$, viele waren $3-4 \mu$ lang und nicht wenige za noch längeren Fäden von $5-7 \mu$ und darüber ausgewachsen, die auch meistens stärker gebogen waren. In ihrer Nähe kamen noch zahlreiche blasse, etwas breitere und leicht banchige Stäbchen vor, die nur an den Contouren schwach gefarbt waren und wohl für in Untergang begriffene Bacillen zu halten sind. In der dichten Eiterinfiltration des Glaskörpers kamen die Bacillen nur selrr spärlieh vor; in der Nähe der Retina und in deren Gewebe, sowie in den übrigen Theilen des Anges wurde vergeblich danach gesucht. Dagegen gelang es jetzt, an der oben bezeichneten Stelle die Bacillen anch dureh Färbung mic Löffler's Methylenblau in der Wärme nachzuweisen. Sie zeigten dabei leichte Ungleichmässigkeiten ihrer Färbung, welche nach. Haematoxylintinction nicht zu bemerken waren.

In Lenkocyten eingeschlossene Bacillen fanden sich nur ganz vereinzelt, und $z w r^{*}$ in dem eitrigen Exsudate dicht linter der Linse. Eine solche Zelle zeigte nach Methylenblaufärbung im Inneren einen einzelnen grossen Bacillus, von $3 \mu$ Länge und fast $1 / 2, \mu$ Dicke, der am eimen Ende ein dunkel gefärbtes Ernst'sches Korn einschloss.

Im Inneren von Gefaissen enthaltene Bacillen kamen auch an diesem Auge nirgends zur Beobachtung.

\section{Epikrise.}

Dass die doppelseitige Augenentzündung im vorliegenden Falle wirklich angeboren war, kann nicht bezweifelt werden, wenn auch die Eigenthümerin des Thieres erst zwei bis drei Tage nach dessen Geburt einen Fehler an den Augen entdeckte und die Untersuchung in der Augenklinik erst am achten Tage des Lebens stattfand. Die weitgediehene Entwickelung des Processes, welche durch die anatomische Untersuchung festgestellt wurde, insbesondere die erhebliche Verändermng der Retina, die starke Eiterinfiltration mit beginnender Schrumpfung des Glaskörpers am linken Auge und die Umknickung der Pupillarzone der Iris, selbst an dem weniger erkrankten rechten, sprechen 
entschieden dafür, dass der Process schon länger als acht Tage gedauert haben musste. Mit dieser Amahme steht auch das Auftreten von angeborener Blindheit und ron Missbildungen des Körpers der Jungen zweier früherer Würfe in vollkommenem Einklang. Viel älter kann aber der Process, nach den gefundenen Veränderungen zu schliessen, anch nicht gewesen sein, zumal die Angen in ihrer Entwickelung gar nicht zurückgeblieben waren; seine Fintstehung wird wohl sicher in die letzte Zeit des Fötallebens zu verlegen sein.

Dass das Mutterthier anscheinend gesund war, kann nicht als ein Beweis gegen eine Uebertragung ron ihm auf die Frucht angesehen werden, da es öfters rorkommt, dass ein anscheinend gesundes Thier dennoch krank ist. Es liegen auch sonstige Beobachtungen von sicher angeborenen Erkrankungen mikrobischen Ursprungs vor, wo die Mutter gesund war, und trotzdem nur eine Uebertragung der Mikrobien von ihr auf den Fötus angenommen werden konnte; so z. B. ein Fall ron Carbonelli'), wo das Kind eine Stunde nach der Geburt an serofibrinöser Peritonitis starb und wo im peritonitischen Exsudat und im Blute Streptocokken nachgewiesen wurden, ohne dass die Mutter Zeichen einer Krankheit dargeboten hatte.

In unserem Falle ist man wegen der bei mehreren auf einander folgenden Geburten beobachteten krankhaften Störungen der Jungen berechtigt, an eine Uteruserkrankung des Mutterthieres zu denken, welche sehr wohl olue auffallende Beeinträchtigung des Allgemeinbefindens bestehen konnte.

Der Fall erinnert an die uns nur aus einem Referat bekannten Ergebnisse der Untersuchungen, welche Bang ${ }^{\text {? }}$ )

1) Carbonelli, Rivista di ostetr. e ginec. 1891. Ref. in Baumgarten's Jahresber. f. 1891, \$. 90.

2) R. Bang, Der infectiöse Abortus der Rinder (dänisch). Maaudssirr. for Dyulaeger. VIIT, p. 146. Ref. in Baumgarten's Jahresber. f. 1896 , S. $521-522$. 
uber die Ursachen des infectiösen Abortus der Kühe angestellt hat, und dies um so mehr, weil das Verhalten der dabei gefundenen Mikroorganismen in doppelter Beziehung, nämlich durch das Vorkommen intrabacillärer Körnchen und die Aufnahme in Zellen, dem in unserem Falle ähnlich ist.

Der Abortus entstelit nach Bang's Untersuehungen bei dieser Krankheit durch einen specifischen desquamativen Katarrh der Uterussehleimhant, bei welchem das in reichlicher Menge vorhandene Exsudat zahlreiche, sehr kleine Bakterien enthält, die theils frei, theils in vergrösserten Zellen eingeschlossen sind. Diese Mikroorganismen, welche als die Ursache der Krankheit anzusprechen sind und daher als Abortusbacillen bezeichnet werden, haben Aehnlichkeit mit Cokken; nähere Untersuchungen zeigten aber, dass es sich um sehwach gefürbte Bacillen handelt, welehe leichter färbbare Körnchen enthalten. Es ist sehr wahrscheinlich, dass dieselben als Ernst'sche Körner aufufassen sind.

Der an den Augen gefundene Krankheitsprocess ist als subacute Panophthalmitis zu bezeichnen, wie sie auch beim Menschen, z. B. in leichteren Fällen pyämischen Ursprungs, oder bei der epidemischen Cerebrospinalmeningitis vorkommt. Die Bezeichnung Panophthalmitis rechtfertigt sich durch die gleichzeitige Erkrankung der Retina und des Uvealtractus, obwohl von letzterem nur die Iris und der Ciliarkörper stärker ergriffen waren, die Chorioidea dagegen am rechten Auge, abgesehen pon einer suprachorioidealen Blutung, ganz frei von Veränderungen war, und am linken Auge im Ganzen wur leicht und nur in geringer Ausdehnung stärker entzündet gefunden wurde.

Die eitrige Infiltration des Glaskörpers ist wohl an beiden Augen theilweise von der Retina und theilweise vom Corpus ciliare herzuleiten. Am linken Auge waren die entzündlichen Veränderungen der Retina so hochgradig und gingen so direct in die des Glaskörpers über, dass die eitrige Infiltration des letzteren zu einem sehr erheblichen Theil dem Gefässsystem der Retina zugeschrie* 
ben werden muss. Auch die starke Leukocyteninfiltration der Wandungen der Netzhautgefässe weist darauf hin, dass hier die Quelle für die Emigration der den hinteren Theil des Glaskörpers einnehmenden Eiterzellen zu suchen ist.

Die eitrige Infiltration im vorderen Theil des Glaskörpers, zwischen Corpus ciliare und Linse und an der hinteren Fläche der letzteren, muss dagegen von dem entzündlich veränderten Ciliarkörper hergeleitet werden; sieht man doch die Leukocyteninfiltration an der Innenfläche der Ciliarfortsätze and in deren Zwischenräumen continuirlich in die des angrenzenden Glaskörpers übergehen, während zwischen der Eiterinfiltration dieser Gegend und der in hinteren Abschnitt des Glaskörpers ein grosser Theil des letzteren von Eiterkörperchen mehr oder minder frei ist.

Die Auswanderung aus den Gefässen des Ciliarkörpers wird auch bestätigt durch den Umstand, dass ein Theil der betreffenden Eiterkörper, wie auch die der vorderen und hinteren Kammer und der Zonulagegend, Pigmentkörnchen enthält, welche sie bei ihrer Wanderung durch das Pigmentepithel bindurch aufgenommen haben müssen, während die Eiterzellen im hinteren Theile des Glaskörpers und an der Innenfläche der Retina davon vollkommen frei sind.

Das soeben über die Herkunft der Eiterzellen Gesagte gilt auch für das rechte Auge, wo der Process viel weniger hochgradig und weniger entwickelt ist, und wo insbesondere die eitrige Retinitis einen viel geringeren Grad erreicht hat; auch hier ist eine doppelte Quelle der Eiterzellen, der Ciliarkörper und die Retina, anzunehmen. Der Pigmentgehalt der aus dem Ciliarkörper stammenden Leukocyten ist hier noch in weiterer Verbreitung nachzuweisen als am linken Auge. Besonders schön entwickelt sind hier überall an den zerstreut liegenden Leukocyten die zablreichen langen und verzweigten amöboïden Fortsätze, welche eine 
Eigenthümlichkeit der Thiergattung darzustellen scheinen, und welche die betreffenden Zellen als in Wanderung begriffene Leukocyten zweifellos charakterisiren.

Für die Entstehung der eitrigen Glaskörperinfiltration sind jedenfalls die im Glaskörper in grosser Menge zur Entwickelung gekommenen Bacillen verantwortlich zu machen, und zwar sowohl für deren Auswanderung aus dem Ciliarkörper, als aus der Retina. Auch die eitrige Retinitis ist zum Theil auf die Wirkung der im Glaskörper zur Entwickelung gekommenen Bacillen zu beziehen. Am rechten Auge, wo in der Retina gar keine Bacillen gefunden wurden, kommt diese Entstehungsweise der Retinitis vorzugsweise, vielleicht sogar ausschliesslich in Betracht, während sich am linken Auge auch die in der Retina entwickelten Bacillen daran betheiligt haben mïssen. An diesem Auge lässt sich stellenweise die chemotaktische Wirkung der Bacillen des Glaskörpers noch deutlich demonstriren: auf der einen Seite der abgelösten Membrana hyaloidea liegt der dicht von Bacillen durchsetzte, sonst zellenfreie Glaskörper, auf der anderen Seite eine schmale Zone dichter Eiterinfiltration, welche sich nach ruickwärts allmählich lockert.

Ueber die Entstehungsweise der eigenthümlichen Zonen dichter Eiterinfiltration und angrenzenden zellenarmen fibrinösen Exsudates, welche oben genauer beschrieben wurden, können wir keine hinreichend sicher gestellte Erklärung geben und verzichten daher lieber, eine Hypothese darüber aufzustellen.

Wie das regelmässige Auftreten der bacillenbaltigen Phagocyten an der Innenfläche der Retina und des Ciliarkörpers an der Grenze der dichten Eiterinfiliration zu erklären ist, darauf werden wir am Schluss der Epikrise näher eingehen.

$\mathrm{Ob}$ die eitrige Iritis eine selbständigere Bedeutung hat, oder ob sie, wie die Cyclitis, nur der Wirkung der 
Toxine der im Glaskörper entwickelten Mikroorganismen zuzuschreiben ist, ähnlich wie bei der Hypopyon-Keratitis von der Hornhaut aus eine eitrige Iritis zu Stande kommt, lässt sich nicht sicher entscheiden. Es spricht dafür der völlige Mangel von Mikroorganismen in der vorderen Augenkammer und in der Iris selbst, sowie die Zunahme der Intensität des Processes nach dem Ciliarkörper hin. Die eigenthümliche Umknickung des Pupillarsaumes der Iris nach rïckwärts, welche am rechten Ange besonders stark ausgesprochen war, ist wohl auf die Zusammenziehung des die hintere Kammer einnehmenden eitrig-ibrinösen Exsudats zuruckzuführen, und deutet ebenfulls darauf hin, dass die Hinterfäche der Iris ciner stärkeren entzindungserregenden Wirkung ausgesetat war, als die vordere.

Nach dem Gesagten scheint uns sicher gestellt, dass die Panophthalmitis durch die im Auge nachgewiesenen Bacillen erzengt worden war; wenigstens dürfte es so weit bewiesen sein, als dies durch blosse anatomische Untersuchung, ohne Culturen und Thierexperimente, möglich ist. Dass wir auf das Sorgfältigste bemüht waren, eine Verunreinigung unserer Präparate durch zufällige mikrobische Eindringlinge zu vermeiden, brauchen wir kaum zu erwähnen; schon das Auftreten eines Theiles der Bacillen im Inneren von Zellen und ibr eigenthümliches morphologisches und tinctorielles Verhalten lässt einen solchen Gedanken gar nicht aufkommen. Die Phagocytose der Bacillen und die nachgewiesenen räumlichen Beziehungen zwischen ihrer Verbreitung und der der Eiterung beweisen direct, dass sie im lebenden Auge rorhanden waren und als Erreger der Entzündung zu betrachten sind.

$\mathrm{Da}$ nirgends mehr Bacillen in Blutgefässen gefunden wurden, so haben wir nur Vermuthungen uber ihre Eingangsstelle. Als eine solche sind am linken Auge gewiss die Gefässe der Retina zu betrachten, welche von allen Mem- 
branen des Auges die stärksten Veränderungen zeigt und deren Gewebe selbst auch Bacillen einschliesst. Aus der Retina gelangten sie in den Glaskörper, in welchem sie sich massenhaft entwickelten and iiber einen grösseren Theil desselben verbreiteten. Dass aber gleichzeitig auch aus den Gefässen des Ciliarkörpers Bacillen in den Glaskörper gelangten, wird durch den Umstand wahrscheinlich gemacht, dass nicht nur unweit der Innenfläche der Retina, sondern auch der des Ciliarkörper's eine fortlaufende Zone bacillenhaltiger Phagocyten vorhanden war. Ein sicherer Beweis ist dies aber nicht, da die Bacillen an der Innenfläche des Ciliarkörpers ebenso gut von solchen abstammen konnten, welche aus der Retina in den Glaskörper gelangt waren.

Dagegen ist am rechten Auge, wo sich die Bacillen ansschliesslich im vorderen Theil des Glaskörpers fanden, mit Wahrscheinlichkeit anzunehmen, dass sie durch die Gefässe des Ciliarkörper's geliefert wurden. Ob ausserdem auch aus den Netzhautgefässen Bacillen in den angrenzenden Glaskörper gelangten, die sich später der Beobachtung entzogen, muss dahingestellt bleiben. Nöthig ist diese Annahme nicht, da die im vorderen Theil des Glaskörpers befindlichen Bacillen sehr wohl für sich allein die nicht sehr starke Retinitis bewirkt haben können.

Die Chorioidea war jedenfalls an beiden Augen nicht oder nur unerheblich primär erkrankt. Für das rechte Auge, wo die Chorioidea gar keine entzündlichen Veränderungen und nur eine kleine suprachorioideale Blutung zeigte, braucht ibberhaupt keine Bacilleninvasion angenommen zu werden. Am linken Auge, wo an einer ganz umschriebenen Stelle eine stärkere interstitielle und flächenhafte Exsudation vorkam, hat eine solche jedenfalls in geringer Ausdehnung stattgefunden, es bleibt aber ungewiss, ob die Bacillen primär in der Chorioidea auftraten oder von der Netzhaut aus in sie hinein gelangten.

Was die Bacillen betrifft, so ist hier vor Allem die 
Frage zu exörtern, ob die Verschiedenbeiten ihres Verhaltens bei den einzelnen Färbungsmethoden und das etwas ungleiche Verhalten an beiden Augen zur Annahme nöthigt, dass es sich um verschiedene Arten handelt, oder ob nur eine einzige Art anzunehmen ist und die Verschiedenheiten in anderer Weise zu erklären sind.

Wir bekennen uns entschieden zu der letzteren Ansicht, vor Allem weil die Annahme doch sehr unwahrscheinlich ist, dass mehr als eine Art ron Mikroorganismen von der Mutter auf den Foetus tibergegangen sei. Fntscheidend ist aber wohl, dass die gefundenen Differenzen keine wesentlichen sind, sondern gerade bei der Gruppe der Pseudodiphtheriebacillen, zu welcher msere Mikroorganismen ihrem Verhalten nach gehören, ehenfalls beobachtet werden, so dass sie mit zur Charakterisirung der letzteren beitragen.

Czaplewski ${ }^{1}$ ) hat ror Kurzem hervorgehoben, dass bei gewissen Bakterienarten, z. B. bei den Diphtheriebacillen, nur die jungen Individuen nach Gram sich färben, während die älteren dabei die Farbe abgeben, und in einem etwas früheren Stadium Körnerfärbung darbieten. Diejenigen Bacillen, welche dabei ihre Farbe abgeben, können noch mit Fuchsin nachgefärbt werden. Der Eine von uns hat dasselbe beobachtet bei der Intersuchung von Xerosisbacillen der Conjunctiva, welche bekanntlich so leicht mit wässerigen Lösungen basischer Anilinfarben gefärbt werden; gewöhnlich bleibt bei der Gram'schen Mothode nur ein kleiner Theil derselben gefärbt, nimmt aber dann mit Fuchsin Färbung an. Mitunter treten, wie schon oben erwähnt, mit der Gram'schen Methode in den schwach getärbten Bacillen die Ernst'schen Körner, meistens an den Enden gelegen, in dunkler Färbung hervor. Dasselbe Verhalten lässt sich an Culturen des Xerosebacillus beob1) Czaplewski, Bemerkungen zur Gram'sehen Methode der Bakterienfärbung. Hygien. Rundschaw. 1896. Nr. 21. 
achten, nur dass dabei die Körner oft grösser und zahlreicher sind; bei Nachfärbung mit Fuchsin glaubt man zwei ganz verschiedene Arten von Bacillen mit einander vermischt zu, sehen, indem blassviolett oder roth gefärbte, dunkelviolette Körner einschliessende Bacillen mit rein roth gefärbten abwechseln.

Aehnliche Bilder werden bekanntlich mit warmer alkalischer Methylenblaulösung, womit sich nur die Ernstschen Körner färben und durch Nachbehandlung mit Fuchsin- oder Bismarckbraunlösung erhalten. Es kommen dabei gewisse Verschiedenheiten im Eintreten der Färbung bei den einzelnen Arten vor, worauf M. Neisser ${ }^{1}$ ) neuerdings eine Methode der Differentialdiagnose von Diphtherieund Pseudodiphtheriebacillen gegründet hat. Es ist hier nicht der Ort, näher auf diese Beobachtungen und auf die Bedeutung der Ernst'schen Körner einzugehen; es sei nur bemerkt, dass diese wohl sicher keine Sporen sind, wofür sie im Anfang angesprochen worden sind.

Mit der Weigert'schen Methode, bei welcher das Anilin den Farbstoff weniger stark entzieht, als der bei der Gram'schen Methode benutzte Alkohol, bleiben die Xerosisbacillen, welche überhaupt Färbung annehmen, mehr gleichmässig gefärbt, gerade wie unsere intracellulären Bacillen.

Für unseren Fall ergiebt sich aus den erwähnten Erfahrungen, dass weder das Fintreten oder Ausbleiben der Färbung mit der Gram'schen Methode, noch das Hervortreten oder Fehlen von Ernst'schen Körnern Merkmale sind, welche die Annahme verschiedener Arten von Bacillen nothwendig machen. Die Verschiedenheiten, welche bei unseren Bacillen vorkommen, stimmen im Gegentheil, ebenso wie ihr ganzes tinctorielles Verhalten, so auffallend

i) M. Neisser, Zur Differentialdiagnose des Diphtheriebacillus. Zeitschr. f. Hyg. XXIV. S. 443.1897. 
mit denen der Xerosis - und Diphtheriebacillen uberein, dass man berechtigt ist, sie auf die gleiche Ursache wie bei diesen zu beziehen. Man koonnte hier den Einwand erheben, dass mit dieser Ansicht der Umstand im Widerspruch zu stehen scheint, dass Löffler's Methylenblau, welches das eigentliche Mittel zur Darstellung der Ernstschen Körner ist, am linken Auge versagte. Fs ist aber labei zu berücksichtigen, dass die Ernst'sche Methode für Trockenpräparate frischer Bacillen und nicht für Schnitte ausprobirt ist, und dass die Mikrobien in Schnitten sich in Allgemeinen schwieriger und auch sonst abweichend verhalten. Es kann dies um so weniger als Gegenbeweis geltend gemacht werden, weil am rechten Auge wenigstens an einer Stelle ein Ernst'sches Korn in einem intracellulären Bacillus durch Methylenblau gefärbt wurde.

Die massenhaft im Glaskörper vorkommenden freien Bacillen, welche sich nach Gram und Weigert nicht färbten, wohl aber mit Methylviolett und Haematoxylin, wïrden demnach als abgestorben zu betrachten sein, während die in den Phagocyten eingeschlossenen, wenn auch vielleicht nicht mehr lebensfähig, doch jedenfalls als noch nicht erheblich postmortal verändert anzusehen wären. Hiermit stimmt die auch sonst gemachte Erfahrung überoin, dass im Glaskörpereiter enthaltene und abgestorbene Mikroorganismen zuweilen durch kein anderes Färbungsmittel als durch Hämatoxylin noch zur Anschaung gebracht werden können. Dass zwischen den zahlreichen abgestorbenen Bacillen des Glaskörpers, wie die Weigertsche Methode ergab, einzelne noch lebensfähige rorkamen, ist ganz ebenso an den Xerosisbacillen des Conjunctivalepithels zu beobachten.

Bei weiterer Auslaugung der Chromatinsubstanz der Bacillen geht zuletzt die Färbungsfähigkeit derselben ganz verloren; ehe dieser Punkt erreicht wird, bleiben nur einzelne Methoden ïbrig, mit denen sich noch eine Färbung 
Angeborene Panophthalmitis mit Bacillenbefund bei einer Ziege etc. 225

derselben erreichen lässt. Dass hierin zwischen beiden Augen gewisse Verschiedenbeiten rorkamen, dürfte nicht von wesentlicher Bedeutung sein. $\mathrm{Es}_{\mathrm{s}}$ ist in dieser Hinsicht zu erwähnen, dass die freien Bacillen zwar durch Haematoxylin an beiden Augen mehr oder minder gefärbt wurden, dass aber am rechten Auge ihre Färbung durch Methylviolett nicht gelingen wollte, welches am linken Auge zum Ziele führte, während umgekehrt am letzteren Löffler's Methylenblau versagte, aber am rechten ein sehr befriedigendes Resultat ergab. Es kann sich hier um zufällige Unterschiede des Erfolges bei den ohnehin schwer färbbaren Bacillen gehandelt haben und vielleicht hätte sich bei weiteren Versuchen, zu denen schliesslich kein Material mehr vorhanden war, ein noch gleichmässigeres Verhalten. beider Augen gezeigt. Doch können sehr wohl auch in dem Entwicklungszustande der Bacillen Umstände vorgelegen haben, welche solche Unterschiede bedingten.

In der That waren auch gewisse Verschiedenheiten in der Entwicklung der Bacillen zwischen beiden Augen vorhanden. Am rechten Auge lagen die Bacillen überall vereinzelt und nirgends in grösserer Menge zu eigentlichen Colonieen an einander gelagert; dafïr erreichten sie hier oft eine viel beträchtlichere Länge und waren nicht selten zu kurzen, gebogenen Fadenstiicken ausgewachsen. Da aber die kleinsten an beiden Augen von gleicher Grösse und Form waren und am rechten auch einzelne intracelluläre Bacillen, einmal selbst mit Ernst'schen Körnchen versehene, vorkamen, so sind diese Unterschiede gewiss nicht auf eine Verschiedenheit der Art; sondern nur der Entwicklung zurückzufübren. Zur Erklärung kann wohl dienen, dass am rechten Auge von vornherein vermuthlich eine viel kleinere Zahl von Bacillen in den Glaskörper gelangte, dass in Folge dessen die entzündliche Reaction erheblich schwächer war; dadurch konnte das Wachsthum der Bacillen ungestörter erfolgen und sie zu grösserer จ. Graefe's Archiv für Ophthalmologie. XVVMI. 1. 
Länge auswachsen, bis ihre weitere Entwickelung durch den Eintritt der Entziindung eine Hemmung erfuhr.

Nach unserer oben gegebenen Erklärung würden die in den Phagocyten enthaltenen Bacillen in besserem Erhaltungszustande sein, als die freien Bacillen im Glaskörper. Wenn dies auffallend erscheinen sollte, so ist daran zu erinnern, dass in Zellen eingeschlossene Mikroorganismen ibre Lebensfähigkeit gar nicht so selten nachgewiesener Maassen behalten, und dass selbst, wenn sie in den Zellen absterben, die Auslaugung ihres Inhaltes weniger leicht und rasch exfolgen wird, als im freien Glaskörper. Es brancht hier nur an das Verhalten der Tuberkelbacillen erinnert zu werden, welche schliesslich im Gewebe oft nur noch im Inneren der Riesenzellen der Färbung zugänglich sind, während man doch nicht annehmen kann, dass alle anfangs vorhandenen Bacillen von Riesenzellen aufgenommen worden seien.

Das regelmässige Auftreten der bacillenhaltigen Phagocyten in einer schmalen Zone, an der Innenfläche des Ciliarkörpers und der Retina, peripher von der dichten Eiterinfiltration des Glaskörperraumes, macht den Eindruck, wls ob es sich um den Beginn eines Resorptionsvorganges handelte, wie er sich einstellt, nachdem der entzündliche Process seine Höhe überschritten hat, und bei welchem die fruher ausgewanderten und abgestorbenen Eiterzellen nebst den dazwischen befindlichen Bacillen von später an die Stelle gelangten Phagocyten aufgenommen wurden. Da die in den Phagocyten eingeschlossenen Bacillen neben und nicht in den gleichzeitig darin enthaltenen Eiterkörperchen liegen, was oft mit voller Deutlichkeit zu sehen ist, so lässt sich annehmen, dass die Bacillen wenigstens bis zu ihrer Aufnahme in die Phagocyten lebensfähig gewesen waren. Nun finden sich zwischen den Phagocyten und in dem angrenzenden eitrigen Exsudat entweder gar keine, oder doch nur sehr spärliche, durch Färbung nachweisbare 
Bacillen vor. Es fragt sich also, ob von vomherein an dieser Stelle keine Bacillen vorhanden waren, und ob die Phagocyten die in ihnen enthaltenen Bacillen an anderer Stelle aufgenommen haben und erst später an ihren gegenwärtigen Ort gelangten, oder ob die Bacillen aus der jetzigen Umgebung der Phagocyten stammten und die übrig gebliebenen ihre Tinctionsfähigkeit einbüssten und sich dadurch dem Nachweis entzogen. Uns kommt die letztere Annahme viel wahrscheinlicher vor, weil das ganze Verhalten der Phagocyten nicht derart ist, dass man ihnen eine Wanderungsfähigkeit zuschreiben möchte, und weil ihre regelmässige Anordnung, in einer die Eiterinfiltration rings umgebenden Zone, an die von sesshaften Riesenzellen in der Tmgebung eines nekrotischen Heerdes erinnert. Da auch aus anderen Gründen angenommen werden muss, dass die freien Bacillen ihre Tinctionsfähigkeit mehr und mehr verlieren, so steht der Annahme nichts im Wege, dass sie sie an dieser Stelle schon vollständig verloren haben, wo sie dem gefässhaltigen Gewebe, von welchem die entzündliche Reaction ausgeht, am nächsten gelegen sind.

Wenn es im vorliegenden Falle auch nur gelungen ist, die Mikroorganismen, welche als die Erreger der fötalen Panophthalmitis zu betrachten sind, im Allgemeinen als zur Gruppe der Pseudodiphtheriebacillen gehörig zu charakterisiren, und wenn auch Versuche iber deren Wachsthumsbedingungen und entzündungerregende Eigenschaften fehlen, so glauben wir doch, dass die mitgetheilte Beobachtung als ein neuer Beitrag zur Pathogenese der fötalen Augenkrankheiten von Interesse ist. Dieselbe ist um so merkwürdiger, weil die angeborene Augenaffection sich nicht auf ein Thier beschränkte, sondern bei zwei verschieden alten Jungen desselben Mutterthieres vorkam und zudem noch mit Missbildungen des Körpers bei zweien dieser Jungen combinirt 
228 Th. Leber und C. Addario, Angeborene Panophthalmitis ete.

war, so dass man also ron einer erblichen Augenerkrankung sprechen kann. Man ersieht hieraus, dass die Erblichkeit fötaler Augenentziundungen auch bei gesundem übrigem Körper auf der Uebertragung einer mikrobischen Krankheitsursache von der Mutter auf den Fötus beruhen kann. Am rechten Auge waren die entzündlichen Veränderungen nicht'so hochgradig, dass nicht eine völlige Rückbildung des Processes ohne zurückbleibende Spuren früherer Entzündung hätte eintreten können. Da es nun in einem solchen Falle anch sehr wohl möglich wäre, dass die Erkrankung des Glaskörpers, ehe sie zur Rückbildung gelangt, eine Ernährungsstörung der Linse und Cataractbildung zur Folge bätte, welche als solche einer Ruickbildung nicht fähig ist, so könnte es kommen, dass die schon vorher abgelaufene Entzindung zur Zeit der Geburt nicht mehr rorhanden wäre, wohl aber deren Folge, die Cataract. Es zeigt dies einen Weg an, auf dem wir vielleicht einmal auch zur Erklärung mancher Fälle von angeborener und erblicher Cataract gelangen können.

\section{Erklärung der Abbildungen auf Tafel VIII, Figur $1-3$.}

Fig. 1. Verticaler Durchschnitt durch das linke Auge. Vergrösserung $2,5: 1$.

An der Innenflache der Retina sieht man die Durchschnitte der flachen $\left(t^{*}\right)$ und welligen $(w)$ Zone eitriger Infiltration als dunkle Linien verlaufen. Haematoxylinfărbung.

Eig. 2. Bacillenhaltige Phagocyten von der Innenfläche des Ciliarkörpers. Die Bacillen enthalten dunkel gefürbte Ernstsche Körner, Färbung nach Gram.

Vergrösserung 1000:1.

Fig. 3. Phagocyten aus der gleichen Gegend, welche ausser Bacillen auch mehrkernige Eiterzellen einschliessen. Färbung mit wässeriger Methylviolettlösung.

Vergrôsserung $1000: 1$. 
Fig. 1. 2,5:1

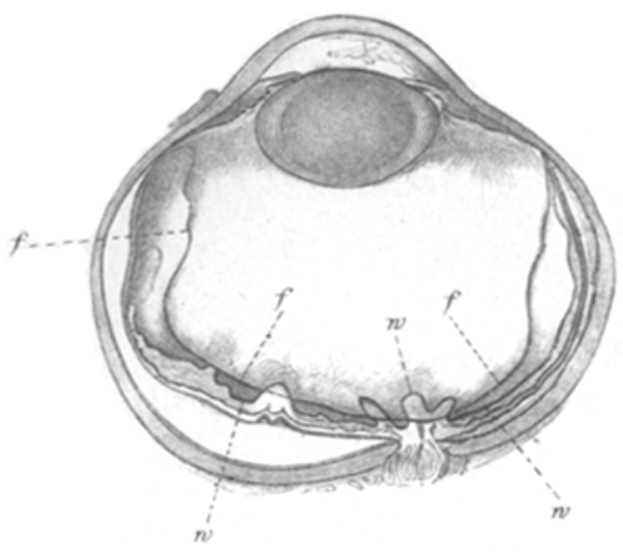

Fig. 2. 1000:1

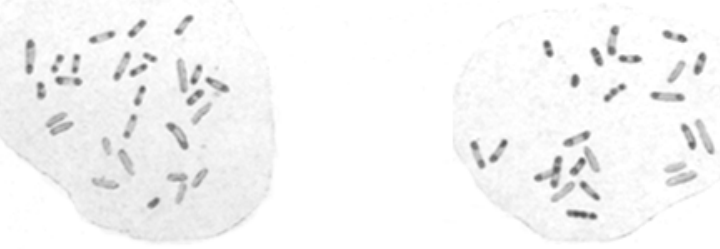

Fig. 3.1000:
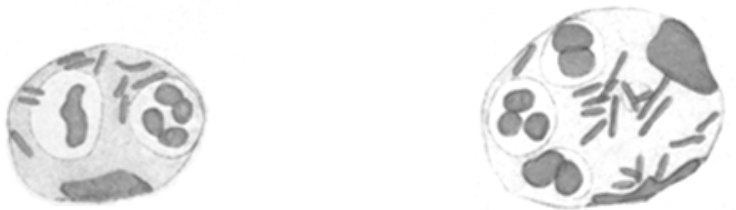

$\because$ : Withelm fingelman! …… 